\title{
Role of Emission Trading and Clean Development Mechanism in Achieving Cleaner Production
}

\author{
Neelima Naik, Seema Unnikrishnan, Anju Singh, and Indrayani Nimkar
}

\begin{abstract}
This paper looks at the various emission trading mechanisms under the Kyoto Protocol. The Emission Trading mechanisms are Clean Development Mechanism (CDM), Emission Trading System (ETS) and Joint Implementation (JI), which involve trading of carbon in terms of Certified Emission Reduction (CER), Assigned Amount Units (AAU) and Emission Reduction Unit (ERU), resp. The paper focuses on CDM which is a flexible project-based mechanism that facilitates Annex I (developed) countries to execute projects to mitigate GHG emissions in non-Annex I (developing) countries to earn CERs. 7677 CDM projects implemented to reduce GHGs from manufacturing industries (384), chemical industries (116), mining and production of metals (97) and energy sector (6576) till October 2015 have been studied and analyzed. All these CDM projects used different methodologies for GHG mitigation activity to calculate Certified Emission Reductions (CERs) generated by CDM project activity in a host country. A brief review of the methodologies used in all the projects to mitigate GHGs by its emission avoidance, capture, recovery and further for electricity generation has been carried out. We have also reviewed the various Joint Implementation Projects and the Emission Trading Volumes briefly. To conclude, it is effective to have CDM projects and JI projects in various industrial sectors as it leads to substantial GHG emission reduction.
\end{abstract}

Index Terms-Emission reduction, carbon trading, chemical and manufacturing industries.

\section{INTRODUCTION}

A manufacturing industrial activity that contributes to economic development, simultaneously leads to high energy consumption and greenhouse gas emissions. However, it also plays a key role in balancing economic development and GHG emissions [1]. There are many opportunities to reduce these GHG emissions due to industrial activities, that include: use of energy efficiency measures, renewable energy sources, clean technologies, recycling and reuse of waste materials (waste heat, gases etc.) in the production process [2]. A Training and social awareness programme makes companies and workers aware of the steps to reduce emissions leaks from the industries. Therefore, sustainable development of the country is possible to be achieved by adopting these measures at manufacturing industry sites.

Many initiatives have been taken at global and local level to reduce GHG emissions. At global level, an international

Manuscript received October 24, 2015; revised January 15, 2016.

The authors are with the National Institute of Industrial Engineering (NITIE), Mumbai, Maharashtra 400087, India (e-mail: neelimanitie@gmail.com, seemaunnikrishnan@gmail.com). treaty was formed formally known as 'United Nations Convention on Climate Change (UNFCCC)'. This convention at its third meeting held at Kyoto, Japan in 1997 adopted Kyoto protocol (KP). In KP developed countries have binding targets of reducing their $\mathrm{GHG}$ emissions below 1990 levels [3]. These targets can be achieved with the help of three carbon emission trading mechanisms under KP. Under these three mechanisms the reduced carbon emissions can be traded in international carbon market. The carbon finance mechanisms are: Joint Implementation (JI), Clean Development Mechanism (CDM) and Emission Trading System (ETS) which involve treading of carbon in terms of Emission Reduction Unit (ERU), Certified Emissions Reductions (CERs) and Assigned Amount Units (AAU) respectively [3]. JI and CDM are project-based mechanisms whereas, ETS is a scheme which helps developed (Annex-I) countries to fulfill their short fallen targets.

Joint Implementation (JI): JI facilitates joint projects between two developed countries only. It was originated from the article 6 of the Kyoto protocol. The eligibility criteria for JI projects include the approval from host party/country and it should provide GHG reduction by sources [4]. There are 2 types of projects under JI i.e. Track 1 and Track 2. It is based on the requirement criteria of the host party. If a host Party meets all of the eligibility requirements to transfer and/or acquire ERUs and verify its emission reductions it is termed as a track 1 project. On other hand if a host Party meets few eligibility requirements, then verification of emission reductions has to be done through the verification procedure under the Joint Implementation Supervisory Committee (JISC) to determine whether the relevant requirements have been met or not. Then host Party can issue and transfer ERUs, and is termed as track 2 projects. 648 (Track1- 597 projects and Track $2-51$ projects) projects have been implemented in various countries under JI till October 2015.

Emission Trading System (ETS): ETS, as set out in Article 17 of the Kyoto Protocol, allows countries that have emission units to spare (emissions permitted to them but not "used") to sell the excess capacity to countries that are over their targets [5]. There are already a number of active carbon markets for GHG emissions such as the European Union Emission Trading Scheme (or EU ETS) in Europe, the largest multi-national GHG emissions trading scheme in the world, the New Zealand Emissions Trading Scheme (NZ ETS) in New Zealand, the Chicago Climate Exchange in United State [6], [7] and more recently the Montreal Climate Exchange in Canada. Carbon taxes and carbon markets (emissions trading) are recognized as the most cost-effective mechanisms [8], [9]. ETS covers more than 11,000 power stations and industrial 
plants under the scheme.

Clean Development Mechanism (CDM): CDM commenced in article 12 of the KP. It is a flexible project-based mechanism that facilitates developed countries to execute projects to mitigate GHG emissions in developing countries to earn CERs. These CERs can be traded and sold in the international carbon market. Developed countries exchange these CERs for money and technology transfer with developing countries. Thus, CDM is for both developed and developing countries. It facilitates developed countries to fulfill their emission reduction targets and gives opportunities to developing countries in revenue generation [10]-[12].

This paper focuses on CDM as we are based in India - a developing country.

\section{Methodology}

This study focused on implementation of 166 CDM projects under chemical and $384 \mathrm{CDM}$ projects under manufacturing, $6576 \mathrm{CDM}$ projects under energy and 97 CDM projects under mining and production of metals sectors to reduce GHGs occurring from various industrial activities. GHG emission causes from all these sectors were studied by analyzing the registered CDM projects; methodologies used for $\mathrm{GHG}$ reduction and estimated emission reductions. Along with CDM, JI and ETS mechanisms have also been studied.

The secondary data about projects was collected from United Nations Framework Convention on Climate Change (UNFCCC) project cycle search, Project design documents (PDDs), Joint implementation, European Union Emissions Trading System, open access journals and various reports.

According to UNFCCC, a total of 7677 projects have been registered under various sectors of CDM till October 2015. Out of these 7677 projects, 384 projects under manufacturing, 116 projects under chemical, 97 projects under mining and production of metals and 6576 projects under energy sectors has been implemented till October 2015 [13], [14].

\section{RESULTS AND DISCUSSION}

\section{A. Analysis of CDM Projects}

\begin{tabular}{|c|c|}
\hline $\begin{array}{c}\text { Countrywise CDM } \\
\text { Projects }\end{array}$ & $\begin{array}{l}\square \text { Algeria } \\
\square \text { Argentina } \\
\square \text { Bosnia and Herzegovina } \\
\square \text { Brazil } \\
\square \text { Chile } \\
\square \text { China } \\
\square \text { Colombia } \\
\square \text { Egypt } \\
\square \text { India } \\
\square \text { Indonesia } \\
\text { Iran (Islamic Republic of) } \\
\square \text { Israel } \\
\square \text { Mexico } \\
\square \text { Pakistan } \\
\square \text { Philippines } \\
\square \text { Republic of Korea } \\
\square \text { South Africa } \\
\square \text { Syrian Arab Republic } \\
\text { Thailand } \\
\square \text { Uzbekistan } \\
\text { 7imbabwe }\end{array}$ \\
\hline
\end{tabular}

Fig. 1. Country wise CDM projects under chemical sector.
Under chemical sector 21 countries have implemented 116 projects with total estimated emission reduction of 57,483,680 metric ton $\mathrm{CO}_{2}$ equivalent $\left(\mathrm{MTCO}_{2} \mathrm{e}\right)$ using 16 methodologies. Under CDM, Manufacturing sector 36 countries implemented 384 projects with total estimated emission reduction of 42,785,932 $\mathrm{MTCO}_{2} \mathrm{e}$ using 26 methodologies. Energy sector has implemented 6576 CDM projects using 77 methodologies with total estimated emission reduction of 707,684,901 $\mathrm{MTCO}_{2} \mathrm{e}$ and mining and production of metals sector has implemented $97 \mathrm{CDM}$ projects using 8 methodologies with total estimated emission reduction of $38,217,800 \mathrm{MTCO}_{2} \mathrm{e}$.

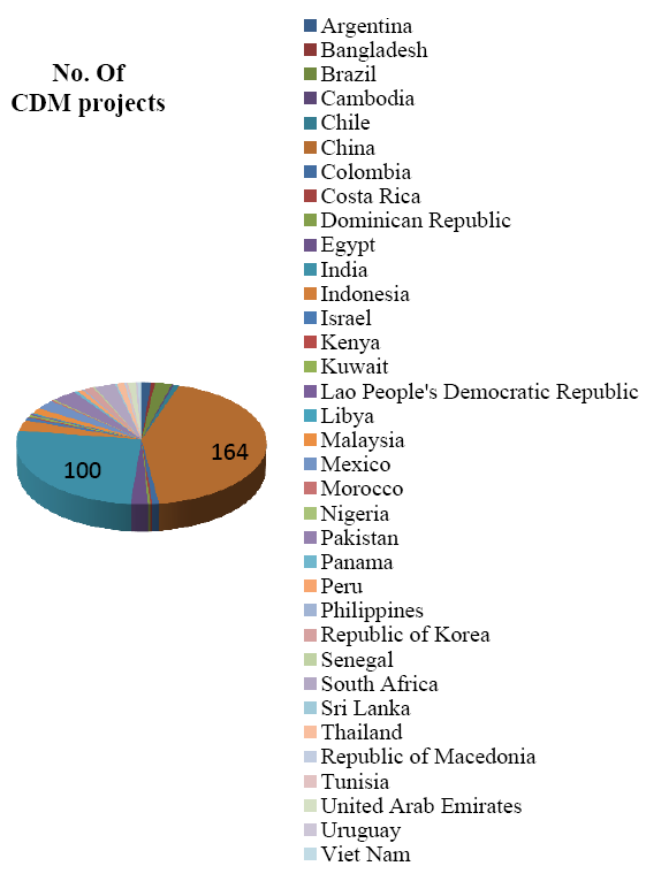

Fig. 2. Country wise CDM projects under manufacturing sector.

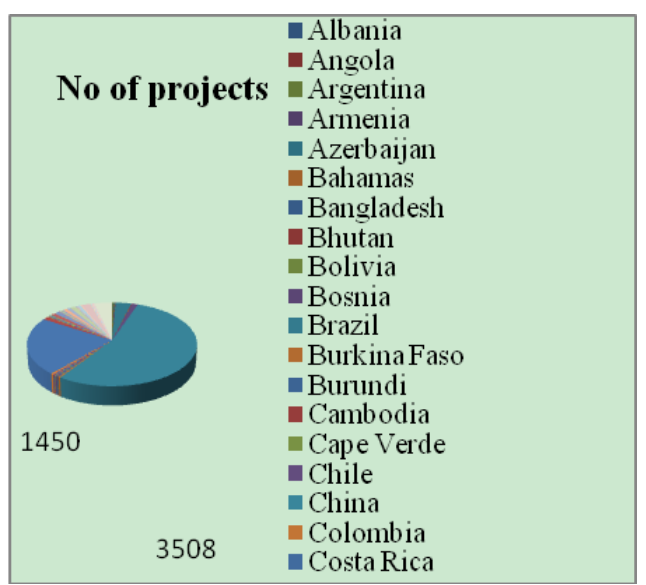

Fig. 3. Country wise CDM projects under energy sector.

In all the sectors, China has implemented maximum projects followed by India. The numbers of projects implemented by China are 51, 164, 3508 and 85 projects under chemical, manufacturing, energy and production of metals sectors respectively. The estimated emission reduction under chemical, manufacturing, energy and production of metals sectors are 25,048,060 $\mathrm{MTCO}_{2} \mathrm{e}$ using 11 methodologies; 24,020,468 $\quad \mathrm{MTCO}_{2} \mathrm{e}$ using 9 methodologies; 460,187,930 $\mathrm{MTCO}_{2} \mathrm{e}$ using 36 methodologies and $35968219 \quad \mathrm{MTCO}_{2} \mathrm{e}$ using 3 methodologies respectively. 


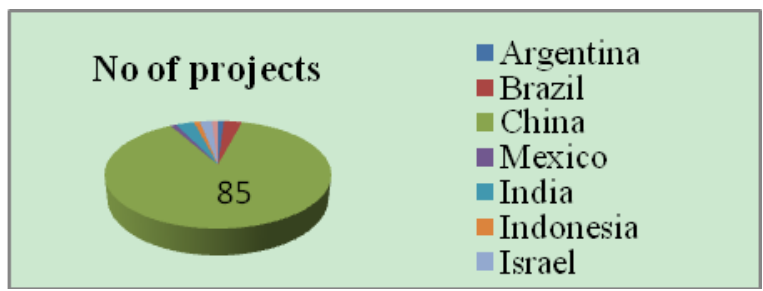

Fig. 4. Country wise CDM projects under metal sector.

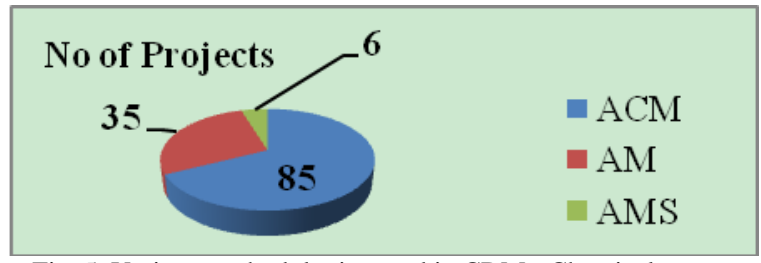

Fig. 5. Various methodologies used in CDM - Chemical sector.

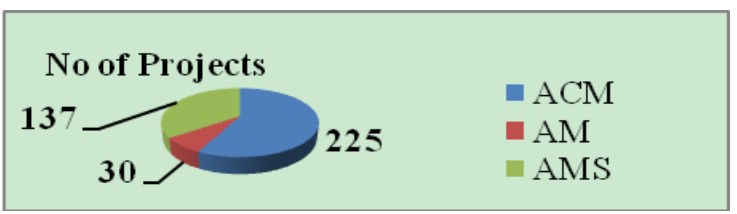

Fig. 6. Various methodologies used in CDM-Manufacturing sector

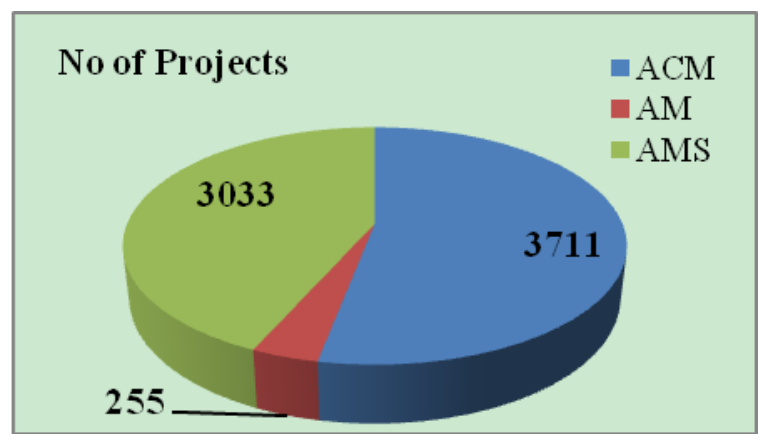

Fig. 7. Various methodologies used in CDM — Energy sector

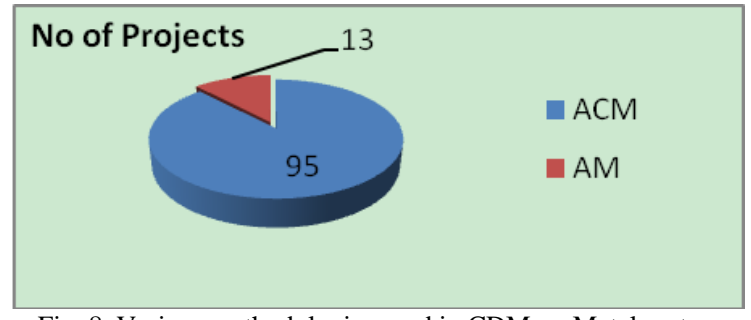

Fig. 8. Various methodologies used in CDM - Metal sector.

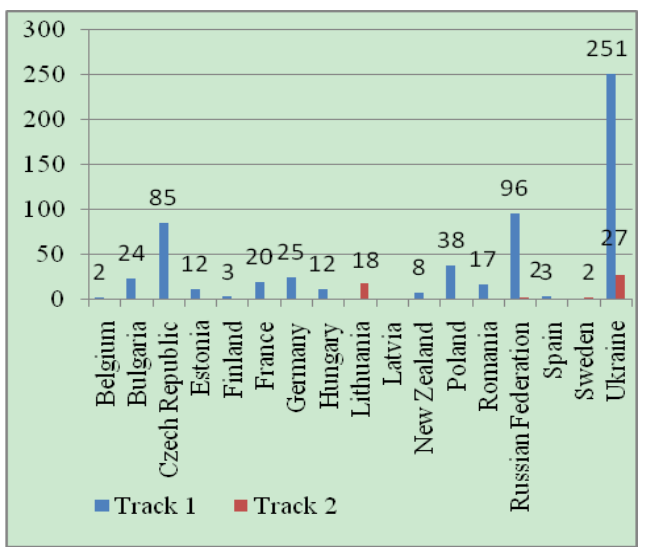

Fig. 9. Country wise CDM projects under JI.

India implemented 11 projects under chemical sector with estimated emission reduction of 2,527,084 $\mathrm{MTCO}_{2} \mathrm{e}$ using 4 methodologies; manufacturing sector 100 projects with estimated emission reduction of 5,088,934 $\mathrm{MTCO}_{2} \mathrm{e}$ using 18 methodologies; energy sector 1450 projects with estimated emission reduction of $93,109,000 \quad \mathrm{MTCO}_{2} \mathrm{e}$ using 40 methodologies whereas under production of metals sector $811,345 \mathrm{MTCO}_{2} \mathrm{e}$ using 2 methodologies (Fig. 1, 2, 3 and 4).

All the CDM projects require baseline and monitoring methodologies for calculation of CERs. There are various categories of these methodologies such as Approved methodologies for large scale projects (AM), Approved methodologies for small scale projects (AMS) and approved consolidated methodologies (ACM). These three categories include various methodologies working on various GHG mitigation principles and are used individually or in combination for GHGs emission reduction from various industrial activities. From the analysis it was observed that many methodologies have been implemented individually or in combination for mitigation of GHGs. The CDM Executive Board approves all baseline-monitoring methodologies which takes around 300 days to get the final approval decision [15]. Renewable energy, landfill gas recovery, biomass and methane recovery [16] are the types of methodologies mostly used in simplified small scale projects which helps reduce the GHG with utilization of natural resources [17]. Use of renewable energy sources, GHG destruction, energy efficiency, fuel or feedstock switch, GHG emission avoidance, displacement of GHG intensive output are the activities used in all these projects to reduce GHG emission from various industrial processes.

Fig. 5 represents various methodologies used in number of CDM projects under Chemical sector. Among the three categories approved methodology for small scale projects (AMS) was used in maximum number of projects. This category includes various methodologies such as AMS-III.H., AMS-III.J., AMS-III.M., AMS-III.O., and AMS-III.Y. Out of these 5 methodologies used in chemical sector, ' $\mathrm{N}_{2} \mathrm{O}$ abatement from nitric acid production (ACM0019)' was used in maximum (83) projects followed by methodology ' $\mathrm{N}_{2} \mathrm{O}$ destruction in the tail gas of caprolactam production plants (AM0028)'. Both the methodologies used in majority of the projects uses GHG destruction as GHG mitigation action. During the implementation of methodology ' $\mathrm{N}_{2} \mathrm{O}$ abatement from nitric acid production (ACM0019)' different abatement measures are used for destruction of GHGs which prevents venting of $\mathrm{N}_{2} \mathrm{O}$ from $\mathrm{N}_{2} \mathrm{O}$ production unit. Before implementation of ' $\mathrm{N}_{2} \mathrm{O}$ destruction in the tail gas of caprolactam production plants (AM0028)' methodology, $\mathrm{N}_{2} \mathrm{O}$ was emitted into the atmosphere during production process. Typical project activity involves installation of a catalytic reduction unit to for destruction of $\mathrm{N}_{2} \mathrm{O}$ emissions in the tail gas of caprolactam production plants [18], [19].

Fig. 6 represents various methodologies used in number of $\mathrm{CDM}$ projects under manufacturing sector. Among the three categories approved consolidated methodology (ACM) was used in maximum number of projects. This category includes various methodologies such as ACM0003, ACM0005, ACM0009, ACM0012 and ACM0021. Out of these 5 methodologies 'Consolidated baseline methodology for GHG emission reductions from waste energy recovery projects (ACM0012)' was used in maximum i.e. 159CDM projects under manufacturing sector, followed by methodology 'Energy efficiency and fuel switching measures 
for industrial facilities (AMS-II.D.)' used in 59 CDM projects. These methodologies use Energy efficiency and Displacement of GHG intensive output as the GHG mitigation action. Methodology ACM0012 is applied in existing or new industrial facility to recover heat from waste; in household facilities this mitigation action is applied by installation of more efficient than already existing electricity generation equipment. With the help of this methodology heat/electricity/mechanical energy are generated by recovery of energy from a waste energy source and are supplied to the grid or applications in the recipient facility. Methodology AMS-II.D improves process energy efficiency in production steps like kiln or furnace, also improves energy efficiency in energy conversion equipments. Thus, this methodology reduces $\mathrm{CO}_{2}$ emission by lowering consumption of electricity, heat and fossil fuels [18], [19].

Fig. 7 represents various methodologies used in number of CDM projects under Energy sector. Among the three categories approved consolidated methodology (ACM) was used in maximum number of projects. This category includes various methodologies such as ACM0001, ACM0002, ACM0004, ACM0006, ACM0007, ACM0008, ACM0009, ACM0010, ACM0011, ACM0012, ACM0013, ACM0017, ACM0018 and ACM0022. Out of these 14 methodologies 'Grid-connected electricity generation from renewable sources (ACM0002)' was used in maximum 3200 projects followed by 'Grid connected renewable electricity generation (AMS-I.D.)'used in 2103 projects. ACM0002 promote installation of a new renewable power plant or the retrofit for reduction of GHG emissions from grid, also promote replacement or capacity addition of an existing renewable power plants. During implementation of this methodology methane emissions from the plant and quantity of electricity supplied are the important parameters to be monitored. AMS-I.D uses Renewable energy as mitigation action. This methodology pertains to use of renewable energy technologies for electricity generation and its supply to grid [18], [19].

Fig. 8 represents various methodologies used in number of CDM projects under mining and production of metals. Among the two categories approved consolidated methodology (ACM) was used in maximum number of projects. This category under mining and production of metals sector includes two methodologies such as ACM0002 and ACM0008. Out of these 2 methodologies used under mining and production of metals 'Abatement of methane from coal mines (ACM0008)'was used in maximum 84 projects followed by methodology 'Grid-connected electricity generation from renewable sources(ACM0002)' used in 11 projects. ACM0008 uses GHG destruction as mitigation action. This methodology captures and destruct coal bed methane, coal mine methane from existing or new coal mines. This methodology pertains to capture and destroyed using oxidation or can be used for power generation. Whereas ACM0002 promote installation of a new renewable power plant or the retrofit for reduction of GHG emissions from grid, also promote replacement or capacity addition of an existing renewable power plant [18], [19].

\section{1) Analysis of JI projects}

Fig. 9 represents country-wise CDM projects under JI. JI has implemented a total of 648 projects in 17 countries with estimated emission reduction of 121,247,195 $\mathrm{MTCO}_{2} \mathrm{e}$. JI projects are further classified as Track 1 and Track 2 projects. Out of 648 projects, 597 projects are Track $1 \mathrm{JI}$ projects in 15 countries with estimated emission reduction of 113,241,709 $\mathrm{MTCO}_{2} \mathrm{e}$ and 51 projects are Track $2 \mathrm{JI}$ projects in 6 countries with estimated emission reduction of $8,005,486$ MT $\mathrm{CO}_{2}$ e.Ukraine has implemented 251 Track 1 projects and 27 Track 2 JI projects with estimated emission reduction of 22,129,218 and 21,185,120 MT $\mathrm{CO}_{2}$ e respectively. Russian Federation has implemented 96 Track 1 projects followed by Czech Republic having 85 with estimated emission reduction of 42,065,829 and 101,921 MT $\mathrm{CO}_{2} \mathrm{e}$ respectively. Under Track 2 JI projects after Ukraine, Lithuania has implemented $18 \mathrm{JI}$ projects with estimated emission reduction of 674,257 MT $\mathrm{CO}_{2} \mathrm{e}$. Among the Track 1 projects ACM0002 and AMS-I.D. have been used in majority projects whereas in Track 2 projects AMS-I.D. and AMS-II.J have been used in majority projects.

\section{B. Analysis of ETS}

World's first international company level trading system launched in 2005 known as European Union (EU) emissions trading system which provide opportunity to reduce carbon dioxide $\left(\mathrm{CO}_{2}\right)$ cost-effectively. In EU ETS, a cap set of potential GHG emission from various companies, factories and power plants is prepared at EU level; companies included in this EU cap set can receive or buy emission allowances which can be traded [20]. EU ETS is operational in 28 countries plus Iceland, Liechtenstein and Norway and with approximately $45 \%$ of the EU's GHG emissions and covers more than 11,000 power stations and industrial plants under the scheme. The cap on emissions from power stations and other fixed installations is reduced by $1.74 \%$ every year from the year 2013. EU targets to reduce its emissions $20 \%$ by 2020 and up to $80-95 \%$ by 2050 compared to 1990 levels. EU ETS development is divided into 4 phases $1^{\text {st }}$ trading period $(2005-2007), 2^{\text {nd }}$ trading period $(2008-2012), 3^{\text {rd }}$ trading period (2013-2020) and $4^{\text {th }}$ trading period (2021-2028). In this system trading can be done directly between buyers and sellers, through several organized exchanges or through the many intermediaries active in the carbon market [21].

\section{CONCLUSION}

All the three mechanisms discussed here, have their strengths and weaknesses. The CDM projects have helped developing countries in achieving sustainable development. JI projects have led to 648 projects being put up jointly by developed countries. Emission trading scheme is going strong with 40 million AAUs being traded everyday [21]. All the three mechanisms together can go a long way in reducing GHG emission.

Till the end of 2012, about 7000 projects were registered in 87 countries and by late June 2013, 1.35 billion CERs had been issued. CDM has lead to an estimated investment of INR 1.6 trillion in India since its inception in 2004. Under the 
Kyoto Protocol India has the second largest number of registered CDM projects. In India, various programs have been initiated through Carbon fund. Under various sectors of CDM projects, many sustainability activities have been implemented. E.g. organization of medical camps, free consultations, distribution of free medicines, mobile dispensary for the surrounding villages; promotion of education by providing notebooks, textbooks, school uniforms and scholarships, improvement of school premises; women empowerment; building community halls, organizing festivals, sports related activities, awareness campaigns, library; land reclamation and trees plantation; rain water harvesting and recycling and reuse of wastewater; soil conservation; building community infrastructure like bore well, check dams, roads, sanitation, public toilets, etc; engaging the local communities for plantation in the plant's vicinity, and imparting vocational training for environmental and social welfare.

Thus, CDM projects have good potential in reducing GHG emissions, encourage sustainable growth and provide economic benefit to the country. CDM projects need continuation.

\section{ACKNOWLEDGEMENT}

The authors gratefully acknowledge the support extended by the NITIE management.

\section{REFERENCES}

[1] H. Fujii and S. Managi, "Which industry is greener? An empirical study of nine industries in OECD countries," Energy Policy, vol. 57, pp. 381-388, 2013

[2] United States Environment Protection Agency (USEPA). 2015. Sources of greenhouse gas emissions, reducing emissions from industry. [Online]. Available: http://www3.epa.gov/climatechange/ghgemissions/sources/industry.ht $\mathrm{ml}$

[3] United Nations. (1998). Kyoto Protocol to the United Nations Framework Convention on Climate Change. [Online]. Available: http://unfccc.int/resource/docs/convkp/kpeng.pdf

[4] United Nations Framework Convention on Climate Change (UNFCCC). (2015). Joint Implementation (JI). [Online]. Available: http://unfccc.int/kyoto_protocol/mechanisms/emissions_trading/items/ 2731.php

[5] United Nations Framework Convention on Climate Change (UNFCCC). (2015). International Emissions Trading. [Online] Available:

http://unfccc.int/kyoto_protocol/mechanisms/emissions_trading/items/ 2731.php

[6] E. Johnson and R. Heinen, "Carbon trading: time for industry involvement," Environment International, vol. 30, no. 2, pp. 279-288, 2004.

[7] J. Peace and T. Juliani, "The coming carbon market and its impact on the American economy," Policy and Society, vol. 27, no. 4, pp. 305-316, 2009.

[8] S. Labatt and R. R. White, Carbon Finance: The Financial Implications of Climate Change, 2007.

[9] Chaabane, A. Ramudhin, and M. Paquet, "Design of sustainable supply chains under the emission trading scheme," International Journal of Production Economics, vol. 135, no. 1, pp. 37-49, 2012.

[10] United Nation Framework Convention on Climate Change (UNFCCC). (2015). About CDM. [Online]. Available: http://cdm.unfccc.int/about/index.html

[11] United Nation Framework Convention on Climate Change (UNFCCC). (2015). The Mechanisms under the Kyoto Protocol: Emissions Trading, the Clean Development Mechanism and Joint Implementation. [Online]. http://unfccc.int/kyoto_protocol/mechanisms/items/1673.php

[12] I. Shishlov and V. Bellassen. (2012). 10 Lessons from 10 years of the CDM. Climate Report, CDC Climate. [Online]. pp. 1-39. Available:
http://www.cdcclimat.com/IMG//pdf/12-10-05_climate_report_37_1 0_lessons_from_10_years_of_cdm.pdf

[13] United Nations Framework Convention on Climate Change (UNFCCC). (September 2015). CDM Insights, Project Activities Facts n Figures. [Online]. Available: https://cdm.unfccc.int/Statistics/Public/CDMinsights/index.html

[14] United Nations Framework Convention on Climate Change (UNFCCC). (2015). CDM Project Cycle Search. [Online]. Available: http://cdm.unfccc.int/Projects/projsearch.html

[15] M. Hinostroza, C. C. Cheng, X. Zhu, J. Fenhann, C. Figueres, and F. Avendano, "Potential and barriers for end-use energy efficiency under programmatic CDM," United Nation Environment Programme, CD4CDM Working Paper Series, 2007.

[16] E. Haites and F. Yamin, "Special feature on the Kyoto protocol: Overview of the Kyoto mechanisms," International Review for Environmental Strategies, vol. 5, no. 1, pp. 199-216, 2004.

[17] R. M. Shrestha and A. M. A. K. Abeygunawardana, "Small-scale CDM projects in a competitive electricity industry: How good is a simplified baseline methodology?" Energy Policy, vol. 35, no. 7, pp. 717-728, 2007.

[18] United Nations Framework Convention on Climate Change (UNFCCC). (2015). CDM Methodologies. [Online]. Available: http://cdm.unfccc.int/methodologies/index.html

[19] United Nations Framework Convention on Climate Change (UNFCCC). (November 2015). CDM Methodologies Booklet. [Online]. Available: https://cdm.unfccc.int/methodologies/

[20] Climate action. (2015). EU ETS 2005-2012. [Online]. Available: http://ec.europa.eu/clima/policies/ets/pre2013/index_en.htm

[21] European Union. (2013). The EU Emissions Trading System (EU ETS), Factsheet. [Online]. Available: http://ec.europa.eu/clima/publications/docs/factsheet_ets_en.pdf

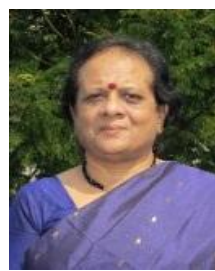

Neelima S Naik was born in Karnataka, India on July 31, 1951. She completed her B.Sc. (Hons) from Pune University in 1971 and the M.S. from Pennsylvania State University, USA in 1973. She completed her doctorate (fellow of NITIE) in the area of environmental noise pollution from National Institute of Industrial Engineering (NITIE), Mumbai, India in 1992.

She is currently working as a professor in NITIE, Mumbai, India and has experience of over 40 years in teaching, research and training in various universities \& institutes in India including NITIE. Her areas of research interest are environmental management, industrial \& environmental noise management and behavioral safety.

Dr. Naik has been reviewer for International Journal of Noise \& Health, International Journal of Environment and Waste Management, International Research Journal of Environmental Sciences, Journal of Environmental Psychology and Journal of Cleaner Production. She has several research publications in the field of Environmental Management and has presented research papers in many International \& National conferences. She was a member of Maharashtra State Environmental Appraisal Committee for 3 yrs.; has been on the Board of Governors of several educational institutes, National Safety Council and Indian Maritime University. She has been a member of Tripartite Awards Committee, DGFASLI, and RAC \& CCFD of National Institute of Miners' Health.

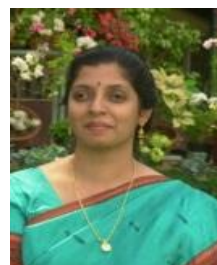

Seema Unnikrishnan was born in Kerala, India on May 3, 1967. She has completed her masters in environmental toxicology from PG Institute of Basic Medical Sciences, University of Madras in 1989; the post graduate diploma in environmental law from Madurai Kamaraj University in 1993 and the doctorate (fellow of NITIE), Mumbai, India, on "A comparative study of Hazardous waste legislation and Management" in 1997.

She is currently working as professor at NITIE, Mumbai, India for the past 21 Years. Before joining NITIE worked for three years for the Central Pollution Control Board. She had several research publications in the field of environmental management. Her areas of research interest are air quality management and cdm; environmentally conscious manufacturing and cleaner production; environmental law and policy, climate change policy life cycle assessment; role of mangroves in disaster reduction.

Prof. Unnikrishnan is life member of National Safety Council; Life Member of Indian Environmental Association; Life Member of National Solid Waste Association; Member of the advisory committee for the Government of Maharashtra for management of biomedical wastes [2012 till date]; One of the expert reviewers for various International journals like the 
Elsevier Journals. e.g. "Journal of hazardous materials", International Journal of sustainable energy etc.; Member of the Jury of BCCI [Bombay Chamber of Commerce and Industry] for corporate citizen award 2014, Member of the Technical committee for Prime Minister's Shram Awards under Ministry of labour and Employment. Government of India (2013-2014).

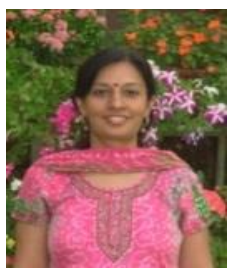

Anju Singh was born in Rajasthan, India, on April 4 1966. She completed her B.Sc. in 1986 and the M.Sc. in 1988 in microbiology from Nagpur University. She received her Ph.D. from Centre for Environmental Science and Engineering, IIT Bombay in 1995.

She is working as an associate professor of environmental management and sustainability at NITIE, Mumbai since 2003. Before joining NITIE she was working in IIT Bombay as scientist (1994-2003) and also in pesticide manufacturing industry as environment \&microbiology officer (1996). He areas of research interest are environmental management; sustainable development and waste management.

Dr. Singh is a member of editorial board of Asian Journal of Microbiology, Biotechnology and Environmental Sciences and several other Indian journals. She won fellowship at Council of Scientific and Industrial Research, all India examination held in 1988. Adjudged Best speaker at Symposium on
'Treatment options of sugar, distillery, paper and allied wastewaters' at IIT Bombay. Dr. Singh was awarded Women of Substance Award in 2010. She has published 30 papers in national and international Journals; 7 book chapters and 106 papers \& 23 posters in national and international conferences.

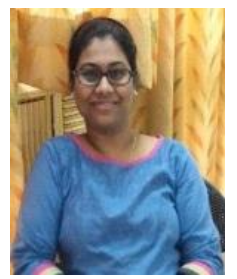

Indrayani Nimkar was born in Mumbai, India on February 3, 1990. She completed her B.Sc. in microbiology in 2010 and the M.Sc. in environmental science in 2012 from University of Mumbai, India.

She is working at Centre for Environmental Studies at NITIE, Mumbai, India as research associate since November 2012. Before joining NITIE, she worked with common effluent treatment plant based at Koparkhairne, Navi Mumbai, India, as a trainee chemist from May 2012 to November 2012. Her areas of interest are waste management, environmenta management and water treatment.

She has published 8 papers in international journals; 2 book chapters and 12 papers $\& 3$ posters in national and international conferences. 